\title{
RELAWAN PAJAK: BAGAIMANA PELATIHAN PAJAK MEMPENGARUHI KEPUASAN WAJIB PAJAK PADA MASYARAKAT URBAN? (STUDI PADA TAX CENTRE UNIVERSITAS PEMBANGUNAN JAYA)
}

\author{
Agustine Dwianika $^{1)}$, Irma Paramita Sofia ${ }^{2)}$ \\ ${ }^{1}$ Fakultas Humaniora dan Bisnis, Universitas Pembangunan Jaya \\ agustine.dwianika@upj.ac.id \\ ${ }^{2}$ Fakultas Humaniora dan Bisnis, Universitas Pembangunan Jaya \\ irma.paramita@upj.ac.id
}

\begin{abstract}
In many countries, taxes are very important for the running of the wheels of government activities. In Indonesia, most of the development budget comes from tax. Therefore tax compliance is very important for the important activities sustainability that have been scheduled. A way to improve tax compliance is to create awareness of taxes early on, continuously and facilitate payment methods or tax reporting by taxpayers. Various ways are carried out by the government to improve taxpayer compliance, including with early tax education and involving young people (millennial) in higher education with the existence of the Relawan Pajak Program (RP). The RP program in the Tax Center (TC) includes several stages, such as socialization, recruitment, training, placement and service also ends with evaluation. The survey conducted by this researcher looked at the effectiveness aspects of the training conducted by TC in collaboration with the Direktorat Jendral Pajak (DJP) in the area of urban society. As a result, training for the effective of RP to help individual taxpayers, but not for corporate taxpayers. So that further, both TC and DJP need to expand the RP training program related to mentoring corporate taxpayer reporting.
\end{abstract}

Keyword : Urban Society, Tax Training, Satisfaction Services, Relawan Pajak, Tax Centre.

\section{PENDAHULUAN}

Gaya hidup masyarakat urban tak lepas dari kesibukan tinggi dan selalu mengikuti perkembangan zaman. Masyarakat di kota besar seperti Jakarta, Bandung, Surabaya dan Semarang memiliki perubahan gaya hidup yang sangat cepat, yang mampu mewakili contoh masyarakat urban. Demikian pula dalam melakukan segala sesuatu, menginginkan proses yang relatif cepat dan praktis, termasuk dalam pemenuhan kewajiban pajaknya yaitu membayar pajak dan melaporkan SPT. Kemudahan membayar dan melapor pajak akan meningkatkan kepuasan wajib pajak, DJP berkomitmen tinggi untuk 
mempermudah pelaporan pajak diantaranya dengan membuat sistem dengan berbasis teknologi yang bisa diakses pada laman www.djponline.go.id. Kesederhanaan sistem pembayaran dan pelaporan Pajak tidak segera dilakukan, dampak negatif juga akan timbul bagi organisasi karena waktu akan tersita habis menangani begitu banyaknya dokumen yang dianggap perlu untuk diawasi (Wibisono, 2019).

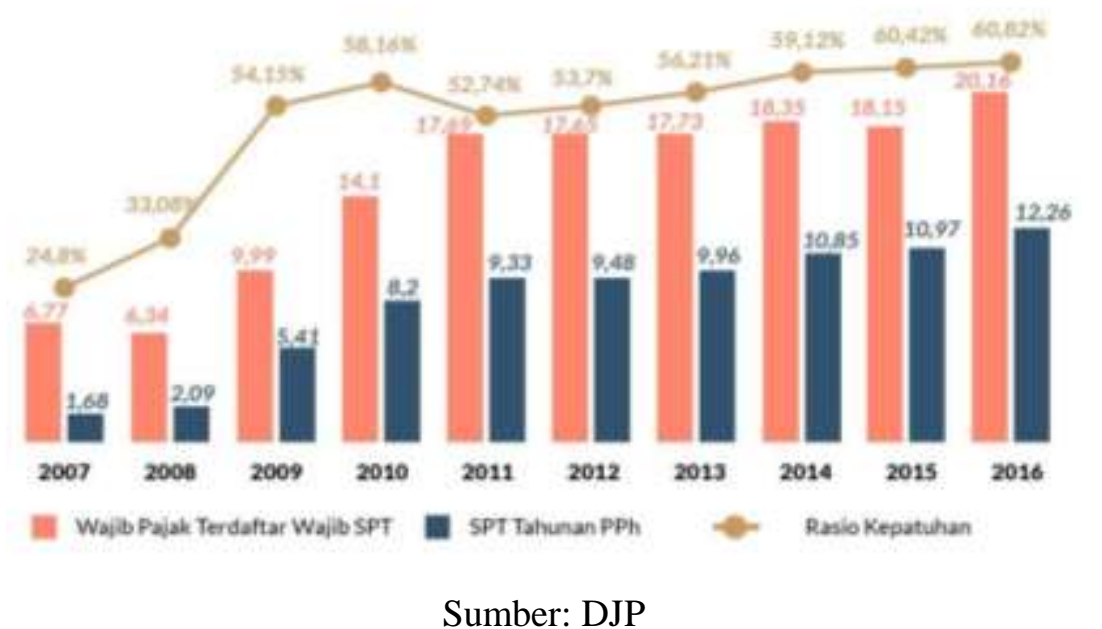

Gambar 1. Rasio Kepatuhan Penyampaian SPT (dalam juta)

Merujuk pada laman tirto.id, memperlihatkan bahwa rasio kepatuhan wajib pajak dalam menyampaikan SPT relatif naik pada 2010, menurun pada 2011 dan cenderung berkisar di angka 56-60\% dari tahun 2013 sampai dengan 2016. Sekarang ini, pemerintah menargetkan kenaikan tax ratio sebesar $15 \%$ pada 2020, yang tentu saja dengan cara meningkatkan kepatuhan penyampaian SPT. Upaya yang tengah dilakukan oleh pemerintah diataranya adalah adanya tax reform (berupa proses bisnis, perbaikan regulasi, sistem administrasi, sumber daua manusia maupun tata kelola organisasi), salah satunya adanya target rasio pajak yang naik secara proporsional dan gradual.

Kepuasan pelayanan akan mampu mempengaruhi tingkat kepatuhan pajak (Asbar et al, 2014). Oleh karenanya sangat penting untuk memberikan pelayanan yang maksimal kepada wajib pajak, guna terus meningkatkan kepatuhan pajak yang pada akhirnya dapat menaikkan pendapatan pajak 
negara. Salah satu langkah strategis yang dilakukan oleh DJP yaitu mengajak 24 perguruan tinggi di Indonesia untuk melaksanakan program Relawan Pajak, yang dimulai pada Maret 2018 lalu dan akan berlanjut pada tahun-tahun berikutnya. Salah satu perguruan tinggi yang terpilih adalah Universitas Pembangunan Jaya (UPJ), yang merespon baik kerjasama dari DJP Kanwil Banten. Melalui Tax Centre, UPJ melakukan sosialisasi dan perekrutan Relawan Pajak dari seluruh mahasiswa dan melakukan seleksi serta pelatihan agar para relawan dapat memberikan pendampingan secara optimal kepada para wajib pajak di lingkungan sekitar yang termasuk dalam kategori masyarakat urban.

Adanya Relawan Pajak yang membantu pendampingan pelaporan pajak berbasis teknologi ini diharapkan mempermudah wajib pajak melaporkan pajaknya. Lingkungan sekitar UPJ yang mayoritas adalah komunitas dari masyarakat urban pada area Bintaro Jaya memiliki karakteristik tersendiri, mereka menginginkan layanan dengan standar yang sangat baik, cepat, ramah, mudah dan murah. Program Pendampingan Relawan Pajak ini menjadi solusi problematika kesulitan pelaporan pajak pada masyarakat urban sebanyak 50 di area Bintaro Jaya. Studi ini melibatkan masyarakat sekitar UPJ yang telah mendapatkan layanan Relawan Pajak Tax Centre UPJ selama 2018-2019. Hasil studi diharapkan dapat memberikan kontribusi bagi peningkatan program Relawan Pajak Tax Centre di Indonesia pada umumnya, dan bagi DJP sebagai penggagas program tersebut secara khusus.

\section{Rumusan Masalah}

Berdasarkan latar belakang yang telah disebutkan diatas, untuk mengetahui seberapa efektif program Relawan Pajak dalam kaitannya dengan masyarakat urban, maka dapat dianalisis permasalah yang ditemukan yaitu:

1. Bagaimana perkembangan Relawan Pajak?

2. Bagaimana pelatihan pajak yang efektif bagi Relawan Pajak?

3. Bagaimana Relawan Pajak dapat membantu wajib pajak? 
4. Bagaimana Relawan Pajak dapat memberikan pelayanan yang memuaskan bagi masyarakat urban?

\section{Tujuan Penelitian}

Studi ini bertujuan untuk memberikan telaah literatur terkait peranan Relawan Pajak pada Tax Centre perguruan tinggi yang telah mendapatkan pelatihan pajak, dengan kepuasan wajib pajak pada masyarakat urban. Materi yang dibahas dalam studi ini adalah perkembangan Relawan Pajak, Pelatihan Pajak, serta Pelayanan Relawan Pajak dalam Program Pendampingan Pelaporan Pajak dengan E-Filing dalam kurun waktu 2 tahun yaitu 2018-2019. Hasil studi ini diharapkan juga bermanfaat bagi ranah praktis, yaitu bagi seluruh Tax Centre yang memiliki komunitas Relawan Pajak, serta bagi pembuat kebijakan seperti DJP agar dapat merumuskan strategi peningkatan kepatuhan pajak yang semakin baik.

\section{TELAAH LITERATUR DAN PENGEMBANGAN HIPOTESIS}

\section{Relawan Pajak}

Komunitas semacam ini juga telah di mulai di negara Canada, mereka menyebutnya the Community Volunteer Income Tax Program (CVITP) dengan kegiatan pelayanan yang lebih luas bahkan sampai pengembalian pajak bagi wajib pajak yang memenuhi syarat (www.canada.ca). Di Indonesia, kegiatan ini melibatkan generasi muda, yaitu mahasiswa dari perguruan tinggi yang memiliki Tax Centre. Kegiatan ini merupakan sinergi Direktorat Jendral Pajak dan perguruan tinggi dalam rangka meningkatkan kesadaran pajak melalui pemberdayaan gerenasi muda Indonesia. Universitas Pembangunan Jaya menjadi salah satu perguruan tinggi yang mengikuti pilot project Relawan Pajak pada 2018 bersama 23 perguruan tinggi lainnya di Indonesia. Para Relawan Pajak UPJ pada akhirnya nanti bertanggungjawab untuk melakukan kegiatan pengabdian masyarakat kepada masyarakat sekitar UPJ, termasuk dalam area Bintaro Jaya yang dapat dikatakan sebagai masyarakat urban.

Guna mempersiapkan Relawan Pajak yang kompeten, sebuah Tax Centre perlu melakukan tahapan berikut: 1) Sosialisasi program kepada seluruh 
mahasiswa pada universitas yang bersangkutan; 2) Melakukan perekrutan anggota komunitas Relawan Pajak oleh Tax Centre; 3) Bekerjasama dengan DJP untuk melakukan kegiatan pelatihan; 4). Melakukan test kelayanan Relawan Pajak dan penempatan; 5). Melakukan pendampingan terhadap wajib pajak dan yang terakhir 6). Evaluasi. Paling tidak memerlukan 2-3 bulan untuk persiapan sosialisasi sampai dengan test kelayakan, dan 1 bulan yaitu pada bulan Maret setiap tahunnya untuk melakukan pendampingan pelaporan pajak, dan kemudian melakukan evaluasi setelahnya.

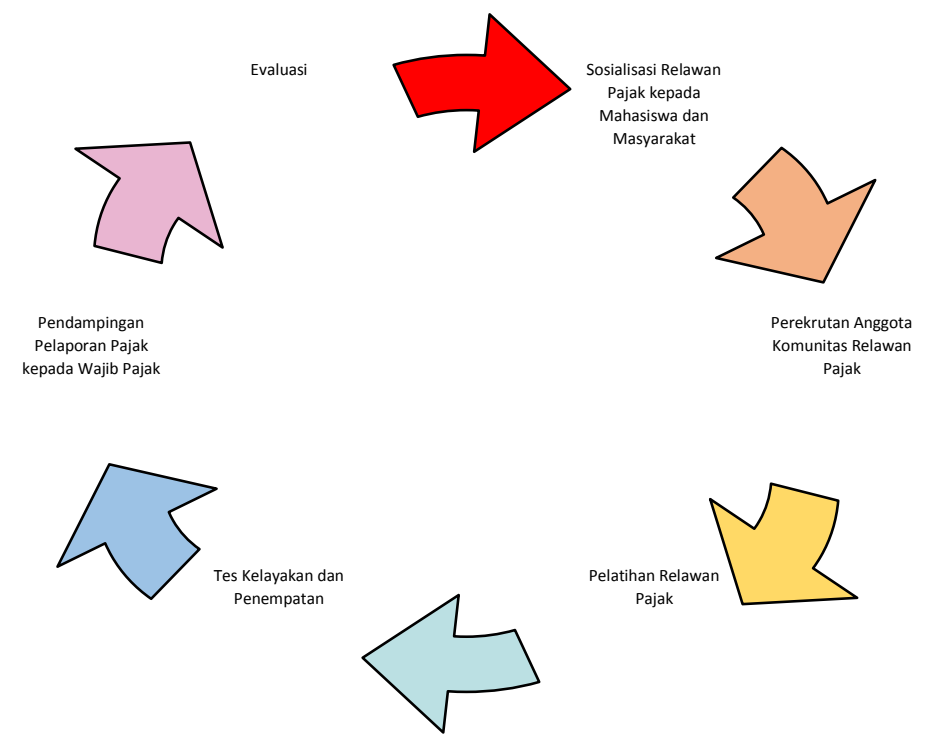

Sumber: Tax Centre UPJ

Gambar 2. Tahapan Relawan Pajak UPJ

\section{Pelatihan Relawan Pajak}

Pelatihan Relawan Pajak UPJ ini memakan waktu kurang lebih selama 2 (dua) bulan, yaitu di Desember-Januari tahun berikutnya. Pada bulan Februari tahun berikutnya, para relawan harus melalui berbagai test untuk dapat dinyatakan sebagai Relawan Pajak yang siap melakukan pelayanan dan ditempatkan pada tingkat tertentu sesuai dengan nilai yang didapatkan. Tingkatan tersebut adalah sebagai supervisor, konsultan dan adminstrasi. Di Tax Centre UPJ sendiri, terdapat 42 Relawan Pajak yang melakukan kegiatan 
pengabdian masyarakat pada wilayaha sekitar UPJ pada tahun 2018, dan 35 Relawan Pajak pada 2019. Penurunan jumlah relawan ini dikarenakan pada tahun 2018 mayoritas relawan merupakan mahasiswa tingkat akhir, sehingga pada tahun berikutnya mereka sudah dinyatakan lulus. Tax Centre UPJ tidak menutup kemungkinan jika bagi para alumni untuk tetap mengikuti kegiatan ini, namun sebagian alumni memutuskan untuk tidak secara aktif mengikuti kegiatan pengabdian masyarakat yang dilakukan, karena alasan pekerjaan.

Pelatihan bagi Relawan Pajak dilakukan di UPJ selama 2 (dua) bulan dari pukul 14.00 hingga 16.00 WIB setiap sesinya. Materi yang diberikan meliputi pengetahuan dasar perpajakan, sampai dengan cara pelaporan SPT WP Pribadi via E-Filing. Dilengkapi pula dengan tambahan materi softskill seperti komunikasi yang efektif dan olah bahasa tubuh. Relawan juga mendapatkan materi pelatihan berupa studi kasus problematika yang biasanya dihadapi oleh para Relawan di lapangan. Para relawan mengikuti kegiatan tersebut dengan penuh antusias dan semangat, karena para mentor dan penyaji materi menyampaikannya dengan cara sederhana sehingga mudah dipahami. Keseluruhan Relawan Pajak yang mengikuti pelatihan dapat mengikuti test kelayakan dengan hasil yang baik. Hal ini menandakan bahwa sistem pelatihan yang digunakan baik, sehingga informasi dalam pelatihan tersebut diharapkan mudah diserap oleh para peserta pelatihan.

\section{Kepuasan Wajib Pajak}

Kepuasan adalah perasaan senang atau kecewa seseorang yang berasal dari perbandingan antara kesannya terhadap kinerja (atau hasil) suatu produk dan harapan-harapan mereka (Kotler, 2005:36). Jika aparat pemerintah meningkatkan mutu pelayanan sesuai espektasi wajib pajak (WP), maka kepatuhan msayarakat akan meningkat dalam kaitannya pembayaran pajak (Ancok, 1988). Sehingga dapat dikatakan bahwa kemampuan untuk dapat diterima, diakui dan dipercaya oleh masyarakat sebagai suatu organisasi yang profesional dalam menjalankan tugasnya merupakan ukuran keberhasilan DJP. Salah satu cara yang dapat dilakukan DJP adalah dengan memberikan kualistas 
layanan yang mampu memberikan pengetahuan dan disiplin paak yang tinggi bagi WP. Sehingga tujuan self assesment yang murni yaitu berupa kesadaran pembayaran pajak dengan benar baik oleh orang pribadi maupun badan dapat tercapai.

Guna mengukur tingkat kepuasan Wajib Pajak terhadap hasil pelatihan kepada para relawan, peneliti menggunakan angket yang dibagikan kepada 50 orang wajib pajak pada masyarakat sekitar UPJ yang telah mendapatkan layanan pendampingan oleh Relawan Pajak UPJ dalam kurun waktu 2 (dua) tahun yaitu selama 2018-2019. Pengukuran tingkat kepuasan wajib pajak adalah menggunakan skala linkert dengan nilai 1 untuk tidak setuju dan 5 untuk sangat setuju.

\section{Masyarakat Urban}

Merupakan masyarakat perkotaan yang memiliki kegiatan utama bukan pertanian, dengan susunan fungsi kawasan sebagai tempat permukiman perkotaan, pemusatan dan distribusi pelayanan jasa pemerintahan, pelayanan sosial, dan kegiatan ekonomi. Kota didefinisikan oleh Sombart (1991) merupakan suatu tempat yang sedemikian besar sehingga tidak saling mengenal satu sama lain. Sebuah desa dapat dikatakan sebagai kota jika terdapat ciri-ciri sosiologis yang merupakan karakteristik dari sebuah kota yaitu heterogenitas masyarakat, mobilitas yang tinggi, kepadatan penduduk, hubungan yang dikembangkan menurut hubungan yang dikembangkan dan lain sebagainya.

Dengan padatnya penduduk perkotaan, maka jumlah wajib pajakpun lebih banyak dibandingkan kawasan pedesaan. Dengan kata lain kepatuhan wajib pajak masyarakat urban menjadi sangat penting dalam mendorong pencapaian target pajak pemerintah. Sebagai contoh di kota besar seperti Jakarta dan kota metropolitan di sekitarnya, banyak terdapat wajib pajak badan mapun wajib pajak pribadi yang memiliki jumlah terutang pajak yang sangat tinggi. Hal tersebut dikarenakan transaksi bisnis yang tinggi, baik lokal, nasional maupun transaksi bisnis intenasional atau antar negara. 
Di sisi lain, masyarakat urban menginginkan segala hal cepat, praktis dan efisien dalam mendukung aktifitasnya yang padat. Termasuk dalam hal pelaporan pajak, mereka menginginkan sistem berbasis teknologi yang mudah dipahami, serta membantu pekerjaan mereka menjadi lebih cepat dan efisien. Menangkap hal itu, DJP menyiapkan sistem perpajakan berbasis teknologi yang mudah digunakan (user friendly) untuk pelaporan pajak, yaitu sistem $e$ Filing. Sistem ini dapat digunakan kapan saja dan dimana saja oleh wajib pajak yang sudah mendaftarkan diri dan mendapatan E-Fin untuk verifikasi akun mereka. Hanya dibutuhkan koneksi internet yang baik, maka pelaporan pajak dapat dilakukan hanya dalam beberapa menit. Jika masyarakat merasa mudah melakukan pelaporan, maka kegiatannya akan lebih cepat, termasuk dalam kaitan transaksi bisnis yang menimbulkan terhutang pajak. Jika sebagian besar masyarakat urban taat pajak, maka kemungkinan pencapaian target pajak pun semakin cepat dan besar.

\section{HASIL PENELITIAN DAN PEMBAHASAN}

\section{Perkembangan Relawan Pajak}

Relawan Pajak (Tax Volunteer) di Indonesia merupakan komunitas yang mempelajari pajak lebih lanjut dan melakukan pengabdian masyarakat berupa pendampingan pelaporan pajak kepada wajib pajak. Merupakan sebuah program yang dicanangkan oleh Direktorat Jendral Pajak dan bekerjasama dengan perguruan tinggi untuk dapat mencetak generasi muda yang sadar pajak, bermanfaat bagi masyarakat dan mendukung visi dan misi pemerintah dalam meningkatkan kepatuhan wajib pajak pada masyarakat sekitar di mana Tax Centre menaungi dan memastikan program kerja Relawan Pajak berjalan baik setiap tahunnya.

Hasil studi membuktikan bahwa Program Relawan Pajak pada Tax Centre Universitas Pembangunan Jaya memiliki peminat yang cukup baik. Perekrutan Relawan Pajak pada tahun 2018 berhasil memberi pelatihan kepada 42 relawan, dan pada tahun 2019 sebanyak 35 relawan. Para relawan memberikan pendampingan kepada wajib pajak masyarakat urban di sekitar wilayah 
perguruan tinggi dengan baik tanpa ada keluhan dari wajib pajak. Dengan menjadi relawan pajak, mahasiswa UPJ memiliki tingkat percaya diri karena memiliki pengetahuan perpajakan yang lebih baik dibandingkan dengan mahasiwa yang tidak memiliki program Relawan Pajak. Mereka juga dapat menularkan pengetahuan perpajakannya kepada rekan mahasiswa lainnya, adik kelas bahkan keluarga dan rekan komunitas lain mereka. Terbukti dari 42 relawan menyatakan 95\% setuju bahwa program Relawan Pajak mampu menaikkan kepercayaan diri mahasiswa.

Relawan Pajak menjadi alternatif pembelajaran pajak yang menyenangkan, mudah dan efektif bagi kaum milenial. Relawan Pajak UPJ sering kali diberikan kesempatan untuk menjadi nara sumber di Majalah Pajak maupun pada rapat koordinasi intenal DJP di berbagai kesempatan. Keikutsertaan aktif Relawan Pajak dalam Seminar Pajak, call paper ataupun seminar pengabdian masyarakat baik yang dilakukan oleh DJP Pusat ataupun Sekolah Tinggi Akuntansi Negara (PKN STAN) menjadi catatan positif tersendiri. Mereka begitu bersemangat meneruskan pengetahuan pajak yang dimilikinya dan melakukan pengabdian masyarakat di masa yang akan datang.

\section{Pelatihan Pajak yang Efektif bagi Relawan Pajak}

Program Relawan Pajak dipandang sebagai sebuah program pelatihan pajak yang tepat bagi para mahasiswa. Hasil studi memperlihatkan $85 \%$ wajib pajak merasa para relawan sudah mendapatkan pembekalan yang baik, sehingga pelaporan mereka dapat mudah, cepat dan efektif. Kemampuan para relawan ini tentu saja atas program pelatihan pajak yang tepat, yang telah dilakukan oleh DJP bekerjasama dengan Tax Centre UPJ. 15\% sisanya menyatakan bahwa mereka berharap para relawan mendapatkan pembekalan untuk pendampingan pelaporan pajak tidak hanya sebatas wajib pajak orang pribadi, namun juga wajib pajak badan.

Pelatihan yang efektif menentukan baik atau buruknya kinerja para relawan. Waktu pelatihan yang cukup, mudah dipahami dan menyenangkan menjadi poin positif yang dianggap mendukung terciptanya pelatihan pajak 
yang efektif bagi para relawan pajak. Pelatihan pajak yang efektif juga didukung dengan personel relawan yang baik. Salah satu proses penting yang perlu diperhatikan agar pelatihan pajak yang efektif adalah pada saat perekrutan calon relawan. Tax Centre UPJ melakukan uji kelayakan baik berupa tes tertulis ataupun tes wawancara yang dilakukan oleh pembina Tax Centre maupun dosen yang dianggap kompeten melakukan uji kelayakan tersebut.

\section{Relawan Pajak dapat Membantu Wajib Pajak}

Hasil survei kepada responden membuktikan bahwa secara keseluruhan adanya Relawan Pajak sangat membantu wajib pajak dalam melakukan pelaporan pajak. Mereka juga terbantu dengan adanya sesi konsultasi baik oleh pembina ataupun oleh para relawan. $100 \%$ responden menyatakan bahwa Relawan Pajak membantu mereka, dan 0\% menyatakan Relawan Pajak tidak membantu mereka. Wajib pajak merasakan layanan tambahan lain yang dilakukan oleh Relawan Pajak tidak hanya sebatas pendampingan pelaporan pajak saja, namun juga layanan atas permasalahan lain seperti belum dimilikinya E-Fin, adanya wajib pajak yang lupa password, sampai dengan diberikannya informasi mengenai cara pembayaran kurang pajak.

Layanan Relawan Pajak dianggap telah memenuhi espektasi wajib pajak masyarakat urban sekitar UPJ. Keluwesan layanan, fasilitas yang cukup baik dan kejelasan informasi dari relawan dapat dirasakan kebermanfaatannya oleh seluruh wajib pajak yang menjadi responden dalam studi ini. Dari hasil evaluasi layanan, ada saran yang diberikan oleh responden berupa diperluasnya area layanan, dan diperbanyakan jumlah relawan sehingga sampai sama sekali tidak ada antrian. Tentu saja masukan ini sangat berharga bagi Tax Centre sebagai pengelola dan DJP sebagai motor dari program ini. 


\section{Relawan Pajak dapat Memberikan Pelayanan yang Memuaskan bagi Masyarakat Urban}

Keseluruhan pertanyaan dalam kuisioner menggunakan skala linkert dengan nilai 1 untuk tidak setuju dan 5 untuk sangat setuju. Atas pertanyaan kepada para responden dengan indikator bahwa Relawan Pajak dapat memberikan pelayanan yang memuaskan bagi masyarakat urban, memperlihatkan bahwa sebanyak $90 \%$ wajib pajak merasa puas dengan layanan Relawan Pajak, dan 10\% nya menyatakan tidak puas. Ketidakpuasan ini dikarenakan responden tersebut merupakan wajib pajak badan atau yang memiliki usaha dan tidak hanya sebatas sebagai karyawan.

Kecenderungan masyarakat urban adalah memiliki kesibukan tinggi atas aktivitas bisnisnya, dan kebanyakan mereka juga memiliki usaha yang berupa Badan Usaha Tetap ataupun karyawan dari perusahaan. Sehingga disamping melaporkan SPT tahunan PPh 21 atas nama pribadi, tak jarang mereka juga memiliki keperluan untuk melaporkan SPT Badan perusahaan yang terkait. $10 \%$ responden tersebut berharap mereka bisa mendapatkan layanan pendampingan pelaporan SPT Pribadi sekaligus menyelesaikan pelaporan SPT Badan perusahaan dimana mereka bekerja.

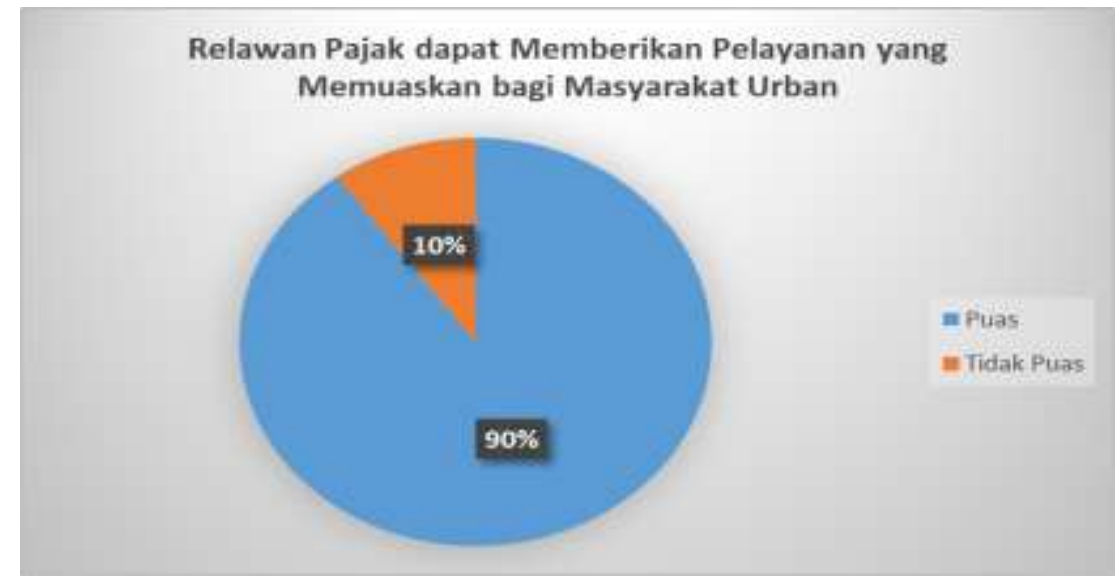

Sumber: Data yang diolah (2019)

Gambar 3. Relawan Pajak dapat Memberikan Pelayanan yang Memuaskan bagi Masyarakat Urban 


\section{SIMPULAN}

Peneliti mempertimbangkan hasil studi dan evaluasi yang telah dilakukan, dan menyimpulkan bahwa pelatihan yang efektif dan efisien dapat mempengaruhi kepuasan wajib pajak berpengaruh pada kepatuhan masyarakat urban secara signifikan. Tingkat kesadaran WP yang tinggi akan kepatuhan pajak dapat mendorong terpenuhinya pendapatan pajak sesuai APBN (pajak.co.id, diakses 14 Oktober 2018). Salah satu alternatif untuk dapat mempermudah pelaporan pajak dengan murah dan efisien adalah dengan memanfaatkan fasilitas pendampingan pelaporan pajak oleh Relawan Pajak. Hal ini didukung dengan adanya hasil evaluasi kinerja Relawan Pajak, sebagian besar responden menyatakan bahwa RP sangat membantu kemudahan pelaporan pajaknya dan berhadap kegiatan serupa akan terus berlanjut di masa-masa mendatang.

Masyarakat urban memiliki kecenderungan mengikuti perkembangan zaman, menginginkan segala sesuatu dengan cepat dan efisien. Pendampingan Relawan Pajak dalam pelaporan pajak bagi wajib pajak masyarakat urban menghadirkan solusi bagi mereka yang sibuk namun menginginkan pelaporan yang praktis dan humis. Kerja sama dengan Tax Centre dan memberdayakan mahasiswa sebagai generasi muda menjadi alternatif yang sesuai dalam rangka meningkatkan wajib pajak yang patuh, karena layanan yang tidak perlu mengantri dan pelayanan yang taktis. Di sisi lain, hal ini dapat meningkatkan kesadaran generasi muda dalam pembelajaran pajak dengan mengikuti pelatihan yang intensif namun menyenangkan bagi kaum milenial.

Masyarakat yang sadar pajak ialah masyarakat yang merasa bangga telah membayar pajak karena berarti ia telah berkontribusi langsung kepada negara Indonesia. Janganlah menjadi free rider yang mau tinggal di tanah Indonesia, menggunakan fasilitas-fasilitas yang ada tetapi tidak mau berkontribusi kepada negara. Dengan Tax Centre yang merupakan salah satu upaya inklusif perpajakan, diharapkan dapat turut mendorong munculnya generasi yang sadar pajak, generasi yang mengenal, mengerti, memahami, dan melaksanakan kewajibannya sebagai wajib pajak, karena pajak untuk kesejahteraan bersama. 
Penelitian ini diharapkan dapat memberikan kontribusi praktis maupun akademis. Yaitu sebagai literasi bagi penelitian serupa tentang kepuasan wajib pajak pada masyarakat urban, yang dikaitkan dengan pelatihan yang diadakan bagi Relawan Pajak yang melakukan pendampingan terhadap wajib pajak secara langsung. Harapan responden kedepannya, pelatihan dan pendampingan tidak hanya dilakukan untuk pelaporan SPT Wajib Pajak Pribadi, namun bisa lebih luas pada pelaporan SPT Wajib Pajak Badan. Pendekatan Program Relawan Pajak ini bisa juga dilakukan sebagai bentuk pendampingan bagi institusi yang membutuhkan layanan pajak dalam lingkup yang lebih kompleks, mengingat sekarang ini jumlah Account Representative (AR) yang ada di KPP masih terbatas, sehingga seorang AR dapat menangani banyak wajib pajak sekaligus, sedangkan permasalahan setiap WP Badan relatif kompleks.

Tentunya artikel ini tidak terlepas dari beberapa keterbatasan antara lain bahwa penelitian ini masih berupa studi kasus dalam lingkup terbatas yaitu Tax Centre Universitas Pembangunan Jaya sebagai unit analisisnya sehingga belum dapat digeneralisasi untuk seluruh Tax Center di Indonesia. Keterbatasan yang kedua adalah rentang waktu yang digunakan untuk menilai kepuasan Wajib Pajak Masyarakat Urban hanya 2 (dua) tahun, sedangkan untuk dapat menilai keberhasilan pelaksanaan Tax Centre kemungkinan diperlukan waktu yang lebih panjang atau lama.

Berdasarkan keterbatasan tersebut maka kami menyarankan kepada peneliti selanjutnya untuk melakukan Analisa efektifitas pelaksanakaan Tax Centre yang memberi dampak pada kepuasan Wajib Pajak msyarakat urban dengan rentang waktu yang lebih lama dengan menggunakan indikator kepuasan yang berbeda dari penelitian ini. 


\section{REFERENSI}

Ancok,D. 1988. Teknik Penyusunan Skala Pengukuran. Yogyakarta : Pusat Penelitian Kependudukan Universitas Gajah Mada.

Asbar . A.K; Fitros, R; dan Rusli. 2014. Pengaruh tingkat kepuasan pelayanan, pemahamanperpajakan, keadilan perpajakan, sanksi perpajakan dan kesadaranperpajakan terhadap tingkat kepatuhan wajib pajak orang pribadi padakpp pratama senapelanPekanbaru. JOM FEKON VOL. 1 NO. 2 OKTOBER 2014.

DJP. Inklusi Kesadaran Pajak dalam Pendidikan. (online).

DJP. Tingkatkan Pelayanan DJP Mekarkan KPP Samarinda.

Fiki. 2017. Penyebab Masyarakat Indonesia Enggan Membayar Pajak Http://bisnisliputan6.com/read/bisnis/perpajakanindonesia. Diakses pada 10 Oktober 2018.

Jotopurnomo, Cindy dan Yenni Mangoting. (2013). Pengaruh Kesadaran Wajib Pajak, Kualitas Pelayanan Fiskus, Sanksi Perpajakan, Lingkungan Wajib Pajak Berada terhadap Kepatuhan Wajib Pajak Orang Pribadi di Surabaya. Universitas Kristen Petra, Surabaya: Indonesia.

Julianto, Pramdia Arhando. (2017). Ditjen Pajak: Kepatuhan Bayar Pajak Masyarakat Indonesia Masih Rendah. Diunduh pada 17 Februari 2018 dari http://ekonomi.kompas.com/read/2017/07/19/193000326/ditjenpajak-kepatuhan-bayar-pajak-masyarakat-indonesia-masih-rendah.

Kundalini, Pertiwi. 2016. Pengaruh Kesadaran Wajib Pajak dan Pelayanan Longdong, Natalia Angelina. 2015. Pengaruh Penyuluhan Perpajakan terhadap Tingkat Kesadaran Wajib Pajak Pada Kantor Pelayanan Pajak Pratama Manado. Manado: Faculty of Economics and Bussiness, Accounting Department Sam Ratulangi University.

Kotler,P.2005 , “Manajemen Pemasaran”, Jakarta :Pabelan Surakarta.

Mardiasmo. 2016. Perpajakan-Edisi Terbaru 2016. Yogyakarta: ANDI.

Martani, Dwi. 2018. Perpajakan. http://dwimartani.com/perpajakan/.Diakses 2 Oktober 2018. 
Menteri Keuangan Republik Indonesia. (2000). Keputusan Menteri Keuangan Republik Indonesia No.544/KMK.04/2000 tentang Kriteria Wajib Pajak yang Dapat Diberikan Pengembalian Pendahuluan Kelebihan Pembayaran Pajak. Jakarta: Indonesia.

Narimawati, Umi. (2008). Metodologi Penelitian Kualitatif dan Kuantitatif, Teori dan Aplikasi. Agung Media, Bandung: Indonesia.

Nazir, Mohammad. (2014). Metode Penelitian. Ghalia Indonesia, Jakarta: Indonesia.

Pranata, Putu Aditya dan Putu Ery Setiawan. (2015). Pengaruh Sanksi Perpajakan, Kualitas Pelayanan dan Kewajiban Moral Pada Kepatuhan Wajib Pajak. E-Jurnal Akuntansi Universitas Udayana Vol. 10 No. 2, Denpasar: Indonesia.

Putriani, Ida Ayu Nyoman dan Budiartha, I Ketut. 2016. "Pengaruh Penyuluhan

Rahayu, Siti Kurnia. (2010). Perpajakan Indonesia : Konsep dan Aspek Formal. Graha Ilmu, Yogyakarta: Indonesia.

Ramadhan, Luqman Yusuf. (2017). Pengaruh Kesadaran, Moralitas dan Budaya Pajak Terhadap Kepatuhan Pajak (Studi Pada UKM Siola Kota Surabaya). Universitas Negeri Surabaya, Surabaya: Indonesia.

Riandi, Muchlisin.2018. Pengertian, Indikator dan Pengukuran Kualitas Audit. Kajian Pustaka. Jakarta.

Robbins, Stephen P. dan Mary Coulter. (2012). Management. Pearson Education, Inc., New Jersey: United States.

Rochaety, Ety, dkk. (2009). Metodologi Penelitian Bisnis. Mitra Wacana Media, Jakarta: Indonesia.

Rohmawati, Alifa Nur dan Ni Ketut Rasmini. (2012). Pengaruh Kesadaran, Penyuluhan, Pelayanan dan Sanksi Perpajakan pada Kepatuhan Wajib Pajak Orang Pribadi. E-Jurnal Akuntansi Universitas Udayana Vol. 1 No. 2, Denpasar: Indonesia.

Santosa, Pandji. (2008). Administrasi Publik: Teori dan Aplikasi Good Governance. PT. Refika Aditama, Bandung: Indonesia. 
Setiawan, Sakina Rakhma Diah. (2013). Tingkat Kepatuhan Pajak Pelaku Usaha Kecil Paling Rendah. Diunduh pada 17 Februari 2018 dari http://ekonomi.kompas.com/read/2013/11/21/1605321/Tingkat.Kepatuh an.Pajak.Pelaku.Usaha.Kecil.Paling.Rendah.

Singarimbun, Masri dan Sofian Effendi. (2015). Metode Penelitian Survei. LP3ES, Jakarta: Indonesia.

Sombart. W. 1991. The Jews and Modern Capitalism. Batoche Books Limtied52 Eby Street SouthKitchener, Ontario N2G 3L1 Canada.

Sugiyono. (2013). Metode Penelitian Kuantitatif, Kualitatif dan $R \& D$. Alfabeta, Bandung: Indonesia.

Sukmana, Yoga. (2016). Kepatuhan Pajak Perusahaan Tambang Memprihatinkan.

http://ekonomi.kompas.com/read/2016/10/27/152333226/kepatuhan.paj ak.perusahaan.tambang.memprihatinkan. Diakses pada 9 September 2018.

Supadmi, Ni Luh. (2009). Meningkatkan Kepatuhan Wajib Pajak Melalui Kualitas Pelayanan. Audi Jurnal Akuntansi dan Bisnis Vol. 4 No. 2, Denpasar: Indonesia.

Tahar, dan Rachman, 2014. Pengaruh Faktor Internal dan Faktor Eksternal Terhadap Kepatuhan Wajib Pajak. Jurnal Akuntansi dan Investasi, Vol. 15, No 1, Januari 2014, Hal : 57-67. Tahun 2016. Yogyakarta: Fakultas Ekonomi, Universitas Negeri Yogyakarta.

Zeithaml, Valarie A., dkk. 2009. Delivering Quality Service. The Free Press, New York City: United States of America. 